\title{
Research on Patent Infringement of Remanufacturing Industry
}

\author{
Deli Cheng \\ Associate professor of law school of Tongji University \\ Shanghai, China \\ cdl@tongji.edu.cn
}

\author{
Chenjun Jia \\ Doctoral student of law school of Tongji University \\ Shanghai, China \\ freejcj@qq.com
}

\begin{abstract}
The development of remanufacturing industry is an important part of circular economy, and also it is the demand for saving resources and protecting environment. If we want to develop remanufacturing industry, we should solve these problems: the ownership of intellectual property (especially patents) and the judgment of intellectual property (especially patents) infringement. This paper analyzes and reviews the patent rights and disputes of remanufacturing industry, and it discusses the relationship between remanufacturing and repair. This paper puts forward proposals for improvement and development of the manufacturing industry, which aims at the deficiency of the current laws and regulations.
\end{abstract}

Keywords-remanufacturing industry; patent infringement; proposals for improvement

\section{INTRODUCTION}

The rapid development of the global economy has caused much unprecedented harm to the natural environment in twenty-first Century. It is imperative to develop circular economy which can save resources and protect environment. Manufacturing industry of large mechanical and electrical products is the most resource consumable, and also it is one of the biggest source of pollution of the environment. The update frequency of mechanical and electrical products is constantly speeding up. We are facing the contradiction between the increasing demand of natural resources and the increasing depletion of natural resources. Remanufacturing industry is born under this premise and condition.

Remanufacturing industry which is based on the original industry repairs and rebuilds waste product by using modern technology means. The industry regards the life cycle of product as judgment basis, and it uses the modern manufacturing techniques, thereby it realizes the goal that the waste products got equivalent quality compared to the original product. Remanufactured products can save the $50 \%$ cost, $60 \%$ energy saving, and material saving $70 \%$, and it almost does not produce solid waste., therefore it is a green and sustainabledevelopment way. According to America remanufacturing industry development report, remanufacturing $1 \mathrm{~kg}$ new materials can save 5-9 kg raw materials, and energy consumption of remanufacturing products is only $15 \%$ of manufacturing new products. According to America Argonne National Key Laboratories, energy consumption of manufacturing a new cars is six times of remanufacturing a car, and energy consumption of manufacturing a new engine is eleven times of remanufacture.

The developed countries have paid special attention to the development of remanufacturing industries. The United States re-manufacturing industry of automobile and engineering machinery accounted for $2 / 3$ of the whole output. Compared with the related manufacturing industry, employment of remanufacturing industry is its 1-3 times. Germany Volkswagen sales ratio of remanufacturing its engine and accessories to its new machine is 9:1 Japan is even more the pioneer of Remanufacturing, and it firstly proposed the remanufacture idea of zero pollution. However remanufacturing industry of china has just started. At the same time China's mechanical and electrical products have entered the peak of scrap, and Tens of thousands of mechanical, electrical and construction machinery products wait for scrapping each year. Developing remanufacturing industry is an inevitable choice to the social sustainable development in china.

There is an unavoidable problem for developing remanufacturing industry ---that is the problem about patent infringement. China has become the world's largest manufacturing plant, and a large number of patented products poured into the market from the factory, so the third party remanufacturing is unstoppable torrent of market economy. Though there is no typical patent infringement case which was caused by remanufacturing in China till now, with China's economic transition patent infringement of remanufacturing will appear in large numbers like the developed countries in Europe and America. Thus the research of this problem has important practical significance.

\section{RESEARCH STATUS}

It is a long-standing problem to patent infringement in remanufacturing industries. The focus of this issue is how to distinguish between repairing and remanufacturing. It is two completely different legal concepts between repairing and remanufacturing in patent law theory, and it is also easy to understand the boundary in theory. It is difficult to distinguish the boundary in the realistic cases because there is fuzziness in fact finding between repairing and remanufacturing caused by the factors of different products and fields. How to correctly distinguish the boundary between them is an dilemma which stumped academia and business circle. 
The domestic scholar Yin Xintian (2005) thinks : the legitimate user of patented product could replace parts of the product for maintaining the normal use of the product if these parts itself has no patent protection, and it is an behavior allowed by law Hu Kaizhong (2006) believes: we should adhere to the principle of taking into account the interest both patentees and consumers, the principle of turning material resources to good account and the principle of forbidding abuse of patent right. Zhang Ling (2007) points out : to judge whether a behavior is to repair or remanufacturing should be put under the background of the social development to consider; the behavior should be judged as repair, if it is to save energy, protect environment, and improve the utilization rate of the product, and vice versa. Xu Binshi (2012) does a comparative analysis to difference of remanufacturing forming technology and remanufacturing forming quality control standards between domestic and foreign. Xiong Zhongkai (2011) discusses the remanufacturing closed loop supply chain coordination mechanism under the patent protection and proposed the contract coordination mechanism that the third party share in the profits and share in costs from remanufacturing. Li Dakai(2013) thinks that the biggest problem of remanufacturing is the deficiency in both integrity and protection of intellectual property rights.

Many famous domestic and foreign scholars put forward some targeted views on how to distinguish the difference between repairing and remanufacturing after painstaking research. Serra Caner Bulmu (2013) deems that remanufacturing is one of creative ways and can save resources and energy. Japan scholar Tamura Yoshino considers that it should take account of three factors to judge whether a behavior constitute patent infringement. The three factors are form, patent right exhaustion, and licensing mode. Tamura Yoshino's view has a certain reference value, but his viewpoint is too theoretical and lacks enough operability in practice.

\section{ChinA'S LEGAL PROVISIONS ON REMANUFACTURING}

Although China patent law has amended for the third time in 2008, the terms of patent infringement almost have not changed. Article 11 of patent law prescribes patent infringement before and after the third time amendment. Article 11 prescribes: After the patent right is granted for an invention or a utility model, unless otherwise provided for in this Law, no unit or individual may exploit the patent without permission of the patentee, i.e., it or he may not, for production or business purposes, manufacture, use, offer to sell, sell, or import the patented products, use the patented method, or use, offer to sell, sell or import the products that are developed directly through the use of the patented method" . Article 69 prescribes, "The following shall not be deemed to be patent right infringement: After a patented product or a product directly obtained by using the patented method is sold by the patentee or sold by any unit or individual with the permission of the patentee, any other person uses, offers to sell, sells or imports that product, $\cdots$." This provision is the specific reflection of patent right exhaustion principle in China's patent law.
China patent law has not prescribed remanufacturing infringement or limit to remanufacturing. So far, China's relevant laws and regulations relating to the reengineering just have two: one is article 27 in Interpretations of the Supreme People's Court on Some Issues concerning the Application of Laws for the Trial of Patent Infringement Dispute Cases (Draft Discussed in Meetings) issued by China's Supreme People's Court in October 27, 2003; the other is article 113 in Opinions on Some Issues Concerning the Judgment of Patent Infringement (for Trial Implementation) issued by Beijing High People's Court in September 29, 2001.

Article 27 in Interpretations of the Supreme People's Court on Some Issues concerning the Application of Laws for the Trial of Patent Infringement Dispute Cases(Draft Discussed in Meetings) prescribes, "For the purposes article 11 and of article 63 of patent Law, manufacturing patent products means processing and making patent products by mechanical or manual mode. The following shall be deemed to be the behavior of manufacturing patent products:(1) Assembling patent products; (2) Collecting patent product parts which have sold and furthermore re-assembling them into patent products; (3) For the purpose of manufacture or business operation, buying back package which are granted designs patent right and used by others to wrap up products of oneself. The following be not deemed to be the behavior of making patent products---- the legal user of patent products do maintenance behaviors like repairing and replacing parts in order to make the patent products to be normally used. "

Article 113 in Opinions on Some Issues Concerning the Judgment of Patent Infringement (for Trial Implementation) prescribes, " Manufacturing this product means product technical solutions which are recorded in patent claims are implemented, including: (1) The products' number, quality and manufacturing method does not affect the judgment of manufacturing behaviors; (2) These behaviors are deemed to be the participating manufacture, and these behaviors include entrusting manufacture to others and marking the wording of supervising-manufacture on the product; (3) Assembling parts into patent products is deemed to be manufacture behavior; (4) Replacing repair for the part of patent products is deemed to be manufacture behavior, or repair action for the patent product whose service life has been over.

\section{REVIEWS ABOUT RELEVANT LAWS AND REGULATIONS}

(1) Deficiency and amending proposals of Interpretations of the Supreme People's Court on Some Issues concerning the Application of Laws for the Trial of Patent Infringement Dispute Cases(Draft Discussed in Meetings)

Firstly, the Interpretations look upon all the assembled patent products as patent infringements, but it does not take into account whether the patent product has scrapped, and it does not also think about the degree of difficulty of assembling the patent product and market demand, etc.

Secondly, it is not reasonable to view collecting patent product parts which have sold and furthermore re-assembling them into patent products as the behavior of manufacturing patent products. The regulation has expanded the scope of 
manufacturing infringement. Though the regulation could across-the-boardly protect patent rights of patentees, it will infringe products users' rights, and the rights is that the user of products repair products in order to maintain the products to be normally used. Because patent products are generally protected by law as a whole, and parts of patent products is impossible to be protected, it will probably hold a part as the whole under this regulation. Besides, as this article describe: maintenance behaviors like normally repairing and replacing parts do not belong to manufacture, and it cannot change the nature of nonmanufacture that parts which used for repair and replacement come from other patent products

Thirdly, we should see the two sides of the problem. In my opinion, though the last sentence could define repair more reasonably, it is not reasonable to define the scope of remanufacturing behaviors. In this case, it is more reasonable to define it as unfair competition behaviors.

This article prescribes, " Behaviors like repairing and replacing parts in order to make the patent products to be normally used are not remanufacturing behaviors, and it is due right in the course of using the product. " This is totally correct, but the article give a very narrow scope of the oblige, just for " the legal user of patent products, " and it greatly reduces the scope of the legal subject of repair.

Based on the above understanding and analysis, the author suggests, " The limitation to repair subject in the third sentence in article 3 should be deleted, and the article should not limit the scope of right subject, and this article should directly prescribe that the following behaviors be not deemed to be the behavior of making patent products----maintenance behaviors like repairing and replacing parts in order to make the patent products to be normally used. Then only if the behavior subject is eligible, and moreover the behavior conforms to the preceding definition, the behavior is regard as legal repair behavior.

I don't think the former sentence is appropriate---- the former sentence is " the following shall be deemed to be the behavior of manufacturing patent products and constitute patent infringement, for the purpose of manufacture or business operation, buying back package which are granted designs patent right and used by others to wrap up products of oneself. " As is stated above, we know that the prerequisite of constituting manufacturing infringement is that the original patent products have completely scrapped, but they are many patent products are recycled and not completely scrapped in real life, so does the package which have been used totally scrap? Maybe the paper-made package can totally scrap, but many glass-made and metal-made packages are not so. For example, a glass wine bottle with which we are very familiar can be used again after simple cleaning and disinfection; furthermore, recycling wine bottles is advocated by green circular economy from the view of saving energy, environmental protection, and cost control. So wine bottles which have been used are not totally scrap under the view of remanufacture. The protection scope of patent rights would be expanded if we take all behaviors of recycling package into the scope of patent infringement without distinction.
(2) Deficiency and amending proposals of Opinions on Some Issues Concerning the Judgment of Patent Infringement (for Trial Implementation)

The deficiency of the Opinions exits in the fourth item in article 113. The former half of the item prescribes that replacing repair for the part of patent products is deemed to be manufacture behavior, but what is the definition of replacing repair? The item is not reasonable. We can only infer that the replacing repair does not include normal repair behavior, but we do not know what behaviors the item would like to limit after all.

Repair and remanufacture respectively have their own objects according to comparison understanding to repair and remanufacture in the text above. Remanufacture aims at the product whose service life cycle is over, but repair aims at the product whose service life cycle is valid and which has not reached the standards for being scrapped, so repair and remanufacture are different behaviors which aim at different stages in the life cycle. We can amend this item as following. For the purpose of manufacture and sale, remanufacturing a new product essentially is manufacture after the patent product has totally scrapped.

The hinder half sentence obviously has contradiction of semantics. The object of repair is products whose service life cycle is valid, but products over service life cycle means scrapping, and scrapped products means discarded products, so it is impossible to repair the product which is discarded. The behavior that restores the use value of products is certainly remanufacturing behavior rather than repair. It will be more appropriate if we use the term remanufacture instead of repair in this item.

\section{PROPOSAL ON ENACTING RELATED RULES}

Through the above analysis, we can see China's legislation lack at present by the above analysis. The lack has the direct relationship with China's economic development----so far there is no related typical case in China, but circular economy is the trend of the world economic development in the future. We should improve China's remanufacturing related laws with predictability. We can roughly see the existing problem and improvement direction through above discussion about the Interpretations and the Opinions.

(1)We should pay great attention to guiding function of principle of rights exhaustion.

Because there are few cases in China's judicial practice at present, and we have no enough practical experience, and there are a huge number of patent in the realistic society, and the situation of each case is different, so the judge could temporarily exercise discretion according to the principle of rights exhaustion, and the judge could do a judgment combining with the actual situation, such as principle of fairness and the principle of turning material resources to good account, etc.

(2)We should strictly define the scope of remanufacture.

The three items in article 27 all discussed above expand the scope of remanufacture infringement. Not every user of patent 
products is able to repair the harmed patent products. In fact, most repairs are done by professional person who is engaged in repair industry. It is not in accordance with the actual and also violates the basic principle of patent law that individual and organization are excluded from the object scope.

(3) Making some enumerated -type interpretations in judicial practice.

We lack related judicial practice experience about the question of repair and remanufacture, so it is approximate that the legislature should make principled provisions at present, and then China's Supreme People's Court makes some more common judgment standards to this problem in judicial interpretations, so that the courts which accepted such cases have certain legal basic to judge this kind of cases. In addition, because of the complexity and particularity of this kind case, the judges should refer to the typical cases of USA, Japan and other developed countries when they are facing these unseen new-type case. Because now in international the patent law of most countries is similar, and furthermore the internationalization of patent infringement cases has been a trend, so there is no more law barrier referring to their related judgment experience. Of course the trial must accord to china's national conditions and the characteristics of cases.

(4) Taking account of economic benefit principle.

If patent products which are the import part of the social wealth are not repaired and directly discarded after harm, this is a great waste to the social wealth. It should take account of social benefit, market demand; turning material resources to good account and improving the economic benefit when we judge it is remanufacture or repair.

\section{CONCLUSION}

It is very urgent to develop circular economy whose body is remanufacturing industry. USA has done the trail research for
150 years, but there is no typical case appearing till now. As the United States Court of Appeals for the Federal Circuit affirmed, there is no exact standard to distinguish repair and remanufacture. Complexity determine that it is impossible for us to make very detailed judgment standard at least now, so we had better to make some principled provisions and also refer to some judgment experience of developed countries. Only in this way can we more exactly determine the nature of the case. That brings a lot of enlightenment to our future legislation: Firstly, we should pay great attention to guiding function of principle of rights exhaustion; secondly, we should strictly define the scope of remanufacture; lastly, China's Supreme People's Court could make some enumerated -type judicial interpretations. Only based on the full consideration of the interests of the patentee and the social public interests and removing the obstacles for remanufacturing industry in law and policy, China's remanufacturing industry could develop fast, and circular economy can operate normally, and China's economy can develop sustainably and healthy.

\section{REFERENCES}

[1] Garetti, M. A. Tool to Estimate Materials and Manufacturing Energy for a Product; IEEE - International Symposium on Sustainable Systems and Technology, Washington, DC,2010.

[2] Boustani, A. Remanufacturing and Energy Savings. Master of Science Thesis, Mechanical Engineering, Massachusetts Institute of Technology, Cambridge, MA, 2010.

[3] 2008.Cheng yongshun. On patent law with case. The intellectual property press. 2008 .

[4] Zheng chengsi. Responsibity of Infringement and compensation for damages. Global law review. 2003.

[5] Xiong zhongkai. The research of Cooperationa model of the remanufacture and dealer. Journal of Industrial Engineering and Engineering Management. 2011(3) 